\title{
Production of monoclonal antibodies against grouper nervous necrosis virus (GNNV) and development of an antigen capture ELISA
}

\author{
J. R. Shieh, S. C. Chi ${ }^{*}$ \\ Department of Life Science and Institute of Zoology, National Taiwan University, Taipei, Taiwan, ROC
}

\begin{abstract}
Five (2 IgG, 3 IgM) monoclonal antibodies (MAbs) against the G9508KS strain of grouper nervous necrosis virus (GNNV) were produced and characterized. All 5 MAbs showed positive signals in the retina of GNNV-infected grouper larvae and in the cytoplasm of GNNV-infected GF-1 cells using immunohistochemistry staining. Two MAbs reacted with the denatured capsid protein derived from GNNV-infected GF-1 cells in Western blot analysis, but did not react with the GNNV recombinant capsid protein expressed by E. coli in an indirect immnunosorbent assay (ELISA). All 5 MAbs were able to neutralize GNNV, tiger puffer NNV (TPNNV) and barfin flounder NNV (BFNNV), while only 2 of the MAbs neutralized striped jack NNV (SJNNV). A capture ELISA system based on the use of MAbs for capture and a rabbit polyclonal antibody for detection was developed. When absorbance values higher than 0.5 were judged to be positive, the sensitivity of the capture ELISA system was $2.5 \mathrm{ng}$ per well of purified GNNV protein or $6.5 \times 10^{4} \mathrm{TCID}_{50}$ per well of GNNV supernatant from culture cells. This capture ELISA system could become a more specific and sensitive tool for NNV diagnosis in the field and in routine laboratories.
\end{abstract}

KEY WORDS: Fish nodavirus · Nervous necrosis virus · Monoclonal antibody · Capture ELISA Resale or republication not permitted without written consent of the publisher

\section{INTRODUCTION}

Viral nervous necrosis (VNN) or viral encephalopathy and retinopahty (VER) is a serious, worldwide fish disease, and has caused mass mortality in more than 34 species of fish at the larval and juvenile stages (Munday et al. 2002, Chi et al. 2003, Hedge et al. 2003). The causative agent of VNN disease is called nervous necrosis virus (NNV), and has been isolated and identified to be a Betanodavirus of Notaviridae, a nonenveloped, small (20 to $30 \mathrm{~nm}$ ) virus with 2 singlestranded, positive-sense RNAs. The larger RNA (1.01 to $1.10 \times 10^{6} \mathrm{Da}$ ) codes for RNA-dependent RNA polymerase $(110 \mathrm{kDa})$, and the small RNA (0.49 to $0.51 \times 10^{6} \mathrm{Da}$ ) codes for the coat proteins (40 to $42 \mathrm{kDa}$ ) (Mori et al. 1992, Comps et al. 1994, Frerichs et al. 1996, Chi et al. 2001). Molecular phylogenetic analysis of the partial coat protein gene has classified fish nodaviruses into 4 genotypes: striped jack
NNV (SJNNV), tiger puffer NNV (TPNNV), barfin flounder NNV (BFNNV) and redspotted grouper NNV (RGNNV) (Nishizawa et al. 1997).

Several methods have been developed for diagnosis of fish nodavirus, including: immunohistochemistry (Le Breton et al. 1997), indirect immunosorbent assay (ELISA) (Arimoto et al. 1992), in situ hybridization (Comps et al. 1996), RT-PCR (Nishizawa et al. 1994) and fish cell line (Chi et al. 1999a). To provide more specific and standardized reference antibodies, monoclonal antibodies against SJNNV and against yellow grouper nervous necrosis virus (YGNNV) were established (Nishizawa et al. 1995, Lai et al. 2001). Moreover, there are 2 neutralizing monoclonal antibodies (MAbs) against SJNNV that have been used to map the neutralizing epitope on the coat protein of SJNNV (Nishizawa et al. 1999) and the MAbs against YGNNV were used to immunolocalize nodavirus in YGNNVinfected fish (Lai et al. 2001). 
In the present study, a series of neutralizing MAbs against the G9508KS strain of grouper nervous necrosis virus (GNNV) propagated in GF-1 cells (Chi et al. 1999a) are described. In addition, these MAbs were applied to develop a capture ELISA system.

\section{MATERIALS AND METHODS}

Virus and cell culture. The GNNV G9508KS strain, an isolate from moribund grouper larvae Epinephelus coioides, Hamilton with VNN disease (Chi et al. 1999b), was used as an immunogen of Balb/C mice. The GNNV was propagated and purified from the infected GF-1 cells as described previously (Chi et al. 1999a, 2001).

TPKag93 (DDBJ accession number D38637), JFIwa98 and SJNag93 (Iwamoto et al. 1999) were used as representatives of 3 genotypes, TPNNV, BFNNV and SJNNV, and were amplified in E-11 cells incubating at $20^{\circ} \mathrm{C}$ (TPNNV and BFNNV) or $25^{\circ} \mathrm{C}$ (SJNNV) (Iwamoto et al. 2000).

Preparation of MAbs. Eight week old Balb/C mice were intraperitoneally (i.p.) injected with $25 \mu \mathrm{g}$ of purified GNNV emulsified in Freund's complete adjuvant, and 4 wk later, were boosted intravenously with a dose of $50 \mu \mathrm{g}$ of purified GNNV without adjuvant. The spleen cells were harvested $3 \mathrm{~d}$ later and fused with mice myeloma cells (FO cell line) at a ratio of 10:1 by using $50 \%$ polyethylene glycol (molecular weight = 1500). Fused cells were resuspended at a concentration of $1 \times 10^{5}$ cell ml $^{-1}$ in growth medium (GM) consisting of RPMI1640 (Flow Laboratories) with 15\% fetal bovine serum (FBS), $2 \mathrm{mM}$ glutamine and $1 \mathrm{mM}$ sodium pyruvate, dispensed into 96-well microculture plates at $0.1 \mathrm{ml}$ well ${ }^{-1}$ and incubated in a $5 \% \mathrm{CO}_{2}$ incubator at $37^{\circ} \mathrm{C}$. The fused hybridoma cells were selected by GM supplemented with hypoxathine $(0.1 \mathrm{mM})$, aminopterin $\left(4 \times 10^{-4} \mathrm{mM}\right)$ and thymidine $\left(1.6 \times 10^{-2}\right.$ $\mathrm{mM}$ ) (GM-HAT) for $2 \mathrm{wk}$, and then screened by indirect ELISA. The positive hybridoma cells were subcloned at least twice using a limiting dilution.

GNNV-specific MAbs in the hybridoma culture supernatants were precipitated by adding a $50 \%(\mathrm{v} / \mathrm{v})$ saturated solution of ammonium sulfate and centrifuging at $8000 \times g$ for $25 \mathrm{~min}$. The precipitate was re-suspended in phosphate buffer (PBS) and then dialyzed overnight. Ascites of selected MAbs were made by i.p. injection of Balb/C mice with $5 \times 10^{5}$ hybridoma cells 2 wk after i.p. inoculation of Prestain $(2,6,10,14$ tetramethylpentadecane, Sigma). The MAb isotypes were determined using an ELISA isotyping kit (SBA Clonotyping system III Catalogue No. 16-808-49) according to the manufacturer's protocol. Ascites containing the IgG isotype MAb was purified by affinity chromatography on protein-A Sepharose CL-4B (Pharmacia) as described by Ey et al. (1978). Ascites containing IgM isotype MAb was purified according to the method of Bouvet \& Pires (1991).

Indirect ELISA. Nunc-EIA (Enzyme-linked Immunosorbant Assay) plates were coated with $0.1 \mathrm{ml}^{-1} \mathrm{ll}^{-1}$ of purified GNNV, diluted to $5 \mu \mathrm{g} \mathrm{ml}^{-1}$ in carbonate buffer (50 mM, pH 9.6). The plates were then washed 3 times in PBS with $0.1 \%$ Tween 20 (PBST) followed by blocking with $3 \%$ bovine serum (BSA) in PBST for $2 \mathrm{~h}$ at room temperature. All subsequent incubations were performed at $37^{\circ} \mathrm{C}$. The plates were drained and incubated for $1 \mathrm{~h}$ with $100 \mu \mathrm{l}$ well $^{-1}$ of the hybridoma supernatants. Serum from the mouse that was used for the fusion served as a positive control, and the cultured medium pooled from FO cells was used as a negative control. After 3 washes with PBST, $100 \mu \mathrm{l}$ well $^{-1}$ of alkaline phosphatase (AP)-conjugated goat antimouse Ig (Kirkegaard and Perry Laboratory, KPL), diluted in blocking solution, was added and incubated for a further $1 \mathrm{~h}$. Finally, after washing, $100 \mu \mathrm{l}$ well ${ }^{-1}$ of chromatic substrate (PNPP: $P$-nitrophenyl phosphate, disodium salt, Pierce) was diluted to $0.1 \%\left(\mathrm{~g} \mathrm{ml}^{-1}\right)$ in a bicarbonate coating buffer. After a 30 min incubation in the dark, a yellow color developed and its optical density (OD) was read at $405 \mathrm{~nm}$ with an ELISA reader (MRXplus, DYNEX Technologies). All immunoassays were carried out in duplicate.

Western blot analysis. The reactivity of MAbs to viral polypeptide was examined by Western blot. After $10 \%$ SDS-polyacrylamide gel (SDS-PAGE) electrophoresis of the purified GNNV, viral polypeptides were electrophoretically transferred to an Immobilon$\mathrm{P}$ transfer membrane (Millipore). The membrane was then blocked with $5 \%$ skimmed milk in tris-buffered saline (TBS) at $37^{\circ} \mathrm{C}$ for $2 \mathrm{~h}$ and cut into strips. The membrane strips were incubated with different hybridoma culture supernatants at $37^{\circ} \mathrm{C}$ for $1 \mathrm{~h}$. After washing with TBST (TBS containing $0.1 \%$ Tween 20), the strips were reacted with biotin-labeled goat antimouse Ig (KPL). The strips were again washed with TBST and then exposed to alkaline phosphataselabeled streptavidin (KPL). Finally, the strips were incubated in BCIP/NBT phosphatase substrate (KPL) for $15 \mathrm{~min}$ in the dark at room temperature. The reaction was stopped by washing with distilled water.

Determination of MAb specificity. Purified infectious pancreatic necrosis virus (IPNV), a heterologous fish pathogen belonging to Birnaviridae, was coated on EIA plates with the same dose as purified GNNV for testing the specificity of the MAbs by indirect ELISA.

Reactivity of MAbs with recombinant GNNV coat protein. The reactivity of the recombinant GNNV coat protein with MAbs established in this study was tested by indirect ELISA. The GNNV coat protein, purified 
from GNNV-infected GF-1 cells, was also coated on ElA plates as a positive control.

Neutralization test. The beta neutralization test (constant virus plus antibody dilutions) was applied to test the neutralization ability of the developed MAbs. In the test, $0.1 \mathrm{ml}$ of $100 \mathrm{TCID}_{50}$ GNNV solution was mixed with an equal volume of serial 2-fold dilutions of cultured medium from each hybridoma clone or the mock medium (negative control). The mixtures were incubated at room temperature for $1 \mathrm{~h}$, and then each mixture was added into 4 wells $\left(0.2 \mathrm{ml} \mathrm{well}^{-1}\right)$ of a 96-well microtitration plate with $60 \%$ confluent of GF-1 cells. Evidence of cytopathic effect (CPE) was checked after $6 \mathrm{~d}$ incubation at $28^{\circ} \mathrm{C}$, and the $50 \%$ neutralization dose $\left(\mathrm{ND}_{50}\right)$ was determined according to the method described by Mahy \& Kangro (1996). The $\mathrm{ND}_{50}$ is defined as the inverse of the highest dilution factor of MAb that results in half of the infected cells showing CPE.

The alpha neutralization test (constant MAb plus virus dilutions) as described by Chi et al. (2003) was used to determine the neutralizing effect of these MAbs against GNNV, SJNNV, TPNNV and BFNNV. Because the CPE of BFNNV-infected GF-1 cells incubated at 15 to $20^{\circ} \mathrm{C}$ was not obvious, we used E-11 cells instead of GF-1 cells in these tests. The culture medium from each hybridoma clone was mixed with an equal volume of serial 10-fold dilutions of virus and was incubated for $1 \mathrm{~h}$. The mixture was then added into the $60 \%$ confluent monolayer of E-11 cells in 96-well plates. The plates were then incubated for $10 \mathrm{~d}$ at $20^{\circ} \mathrm{C}$ for BFNNV and TPNNV, $25^{\circ} \mathrm{C}$ for SJNNV and $28^{\circ} \mathrm{C}$ for GNNV. The neutralization index (NI) was determined as the difference between the titers of the control (without MAb treatment) and MAb-treated samples. The neutralization effect was expressed as $\log _{10} \mathrm{NI}$ and was considered significant when $\log _{10} \mathrm{NI}$ exceeded 1.7 (Mahy \& Kangro 1996).

Immunohistochemistry. Piscine nodavirus was immunolocalized by anti-GNNV MAb combined with an avidin biotin complex technique (UltraTech AP Straptavidin-Biotin Universal Detection System, Immunotech). The GNNV-infected GF-1 cells were first fixed by Canoy's solution (acetic acid:methanol $=1: 3$ ) $24 \mathrm{~h}$ post-viral infection. The grouper larvae Epinephelus coioides, Hamilton used for this assay were experimentally infected with GNNV by i.p. injection, and the eyes of the infected larvae were collected 1 wk post infection. The eyes were fixed in neutral phosphatebuffered $10 \%$ formalin, then dehydrated and embedded in paraffin. The paraffin sections of $6 \mu \mathrm{m}$ thickness were deparaffinized at $60^{\circ} \mathrm{C}$ for $30 \mathrm{~min}$, washed in 3 xylene baths, rehydrated through a graded ethanol series, and rinsed in distilled water. The sections were blocked with blocking agent at $37^{\circ} \mathrm{C}$ for $15 \mathrm{~min}$. After rinsing with TBS, the primary antibodies, the 5 GNNVspecific MAbs, or the IPNV-specific rabbit antiserum (as a negative control) were added and incubated at $37^{\circ} \mathrm{C}$ for $1 \mathrm{~h}$. After washing with TBS, the secondary antibody, the biotinylated polyvalent antibody, was added and incubated at $37^{\circ} \mathrm{C}$ for $10 \mathrm{~min}$. After washing, AP-conjugated streptavidin was added, and incubated at $37^{\circ} \mathrm{C}$ for $10 \mathrm{~min}$. Finally, chromogen was added and the color was allowed to develop for $5 \mathrm{~min}$. The sections were then washed in distilled water, counterstained by hematoxylin and mounted for examination via light microscopy.

Capture ELISA. MAbs developed in this study were applied to construct a capture ELISA, also known as the double antibody sandwich ELISA. GNNV-specific MAbs were used as capture antibodies coated on the EIA plates and GNNV-specific rabbit polyclonal antibodies (RPAbs) were used as secondary antibodies (detection antibodies). Optimal concentrations for the combinations of MAb and RPAb were tested by checkerboard titration. It was found that $0.03 \mu \mathrm{g}$ well ${ }^{-1}$ of MAb and $0.1 \mu \mathrm{g}$ well ${ }^{-1}$ of RPAb was the best combination, and was used for the following sensitivity tests of the MAb 9D (IgM) or MAb 2E (IgG). A constant MAb concentration $\left(0.03 \mu \mathrm{g} \mathrm{well}^{-1}\right)$ plus virus dilutions were further used to compare the sensitivity of indirect and capture ELISA. In addition, PBS with a $\mathrm{pH} 7.0$ was found to be more suitable as a coating buffer for the GNNV-specific MAb than carbonate buffer with a $\mathrm{pH}$ 9.6.

For capture ELISA, the 96-well EIA plates were coated with a capture antibody, $0.03 \mu \mathrm{g} \mathrm{well}^{-1}$ of purified anti-GNNV MAb and were incubated at $4^{\circ} \mathrm{C}$ overnight. After washing with PBST, the EIA plates were blocked with $3 \% \mathrm{BSA}$ and incubated at $37^{\circ} \mathrm{C}$ for $2 \mathrm{~h}$. After rinsing with PBST, purified GNNV or GNNV containing culture supernatant from infected GF-1 cells was added, and incubated at $37^{\circ} \mathrm{C}$ for $3 \mathrm{~h}$. After washing, $100 \mu \mathrm{l}$ of secondary antibody, $0.1 \mu \mathrm{g}$ well $^{-1}$ of purified RPAb, was added and incubated at $37^{\circ} \mathrm{C}$ for $1 \mathrm{~h}$. After rinsing with PBST, $100 \mu \mathrm{l}$ of APconjugated goat anti-rabbit Ig (KPL) was added. After $1 \mathrm{~h}$ incubation at $37^{\circ} \mathrm{C}$, the plates were washed and an enzymatic reaction developed by adding the substrate, PNPP (Pierce) for $30 \mathrm{~min}$.

\section{RESULTS}

\section{Production and characterization of MAbs}

Thirty-three ELISA-positive MAbs against GNNV were successfully cultured, and 5 of the MAbs showed good neutralization ability. $\mathrm{ND}_{50}$ of MAb $2 \mathrm{E}, 9 \mathrm{~B}, 9 \mathrm{D}$, 10G, $12 \mathrm{E}$ against $100 \mathrm{TCID}_{50}$ GNNV were $2^{6}, 2^{15}, 2^{14}, 2^{6}$ and $2^{14}$ (Table 1 ). Isotype determination showed that 
MAbs 2E and 10G were the IgG1 isotype with a $\lambda$ light chain, while MAbs 9B, 9D and $12 \mathrm{E}$ were of the IgM isotype with a $\kappa$ light chain. Moreover, all 5 MAbs showed high specificity to GNNV and the OD values of these MAbs with IPNV were as low as the negative control.

\section{Properties of the epitopes recognized by MAbs}

The Western blot analysis indicated that MAbs 9D and 10G recognized the coat protein of GNNV purified from GNNV-infected GF-1 cells in the denatured form. MAbs 2E, 9B, 12E failed to react with any viral polypeptide on the transferred membrane.

The ability of the GNNV-specific MAbs to react with the recombinant GNNV coat protein was tested by indirect ELISA. Recombinant GNNV coat protein expressed by E. coli, and puri-
Table 1. Characteristics of the 5 monoglonal antibodies (MAbs) against the grouper NNV G9508KS strain. $\mathrm{ND}_{50}: 50 \%$ neutralization dose; pGNNV: purified grouper nervous virus (GNNV) from infected GF-1 cells; rGNNV: recombinant GNNV capsid protein expressed in Escherichia coli; pIPNV: purified infectious pancreatic necrosis virus from infected GF-1 cells

\begin{tabular}{|lcccccc|}
\hline MAbs & ND $_{50}$ & Isotype & $\begin{array}{c}\text { Western blot } \\
(\mathrm{pGNNV})\end{array}$ & $\begin{array}{c}\text { ELISA } \\
\text { (rGNNV) }\end{array}$ & $\begin{array}{c}\text { ELISA } \\
(\mathrm{pGNNV})\end{array}$ & $\begin{array}{c}\text { ELISA } \\
(\mathrm{pIPNV})\end{array}$ \\
\hline 2E & $2^{6}$ & IgG1, $\lambda$ & - & + & + & - \\
9B & $2^{15}$ & IgM, $\kappa$ & - & + & + & - \\
$9 \mathrm{D}$ & $2^{14}$ & $\operatorname{IgM}, \kappa$ & + & - & + & - \\
10G & $2^{6}$ & IgG1, $\lambda$ & + & - & + & - \\
12E & $2^{14}$ & IgM, $\kappa$ & - & + & + & - \\
\hline
\end{tabular}

Table 2. Neutralization indices of monoclonal antibodies (MAbs) reacted with 4 NNV strains in E-11 cells. Values are $\log _{10}$ NI (neutralization index [NI = viral titer before MAb treatment/viral titer after MAb treatment). Values above 1.7 are considered to show good neutralization, between 1.0 and 1.6 questionable neutralization, and below 1.0 no neutralization

\begin{tabular}{|lccccc|}
\hline \multirow{2}{*}{ Virus } & \multicolumn{7}{c|}{ Neutralizing MAbs } & 9D & $10 \mathrm{G}$ & $12 \mathrm{E}$ \\
\cline { 2 - 6 } & $2 \mathrm{E}$ & $9 \mathrm{~B}$ & 6.5 & 3.0 & 7.0 \\
\hline GNNV & 3.0 & 6.3 & 1.6 & 3.6 & 1.3 \\
SJNNV & 4.5 & 1.0 & 3.0 & 3.5 & 3.0 \\
TPNNV & 4.0 & 2.3 & 3.6 & 4.0 & 3.8 \\
BFNNV & 3.8 & 2.8 & & & \\
\hline
\end{tabular}
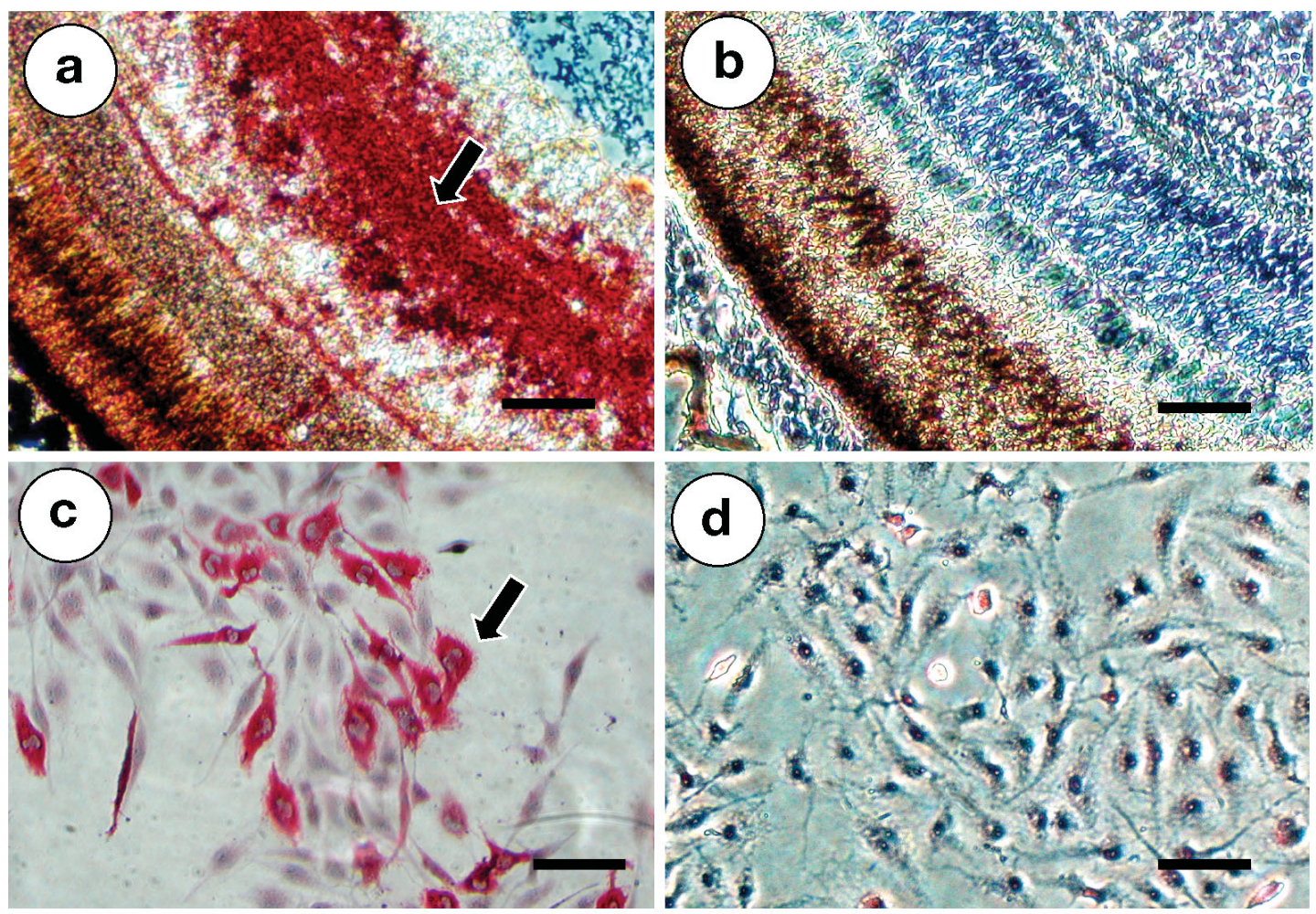

Fig. 1. Detection of grouper nervous nerosis virus (GNNV) in paraffin sections of experimentally GNNV-infected grouper eye and in GNNV-infected GF-1 cells by immunohistochemistry (IHC) staining with GNNV-specific MAb. All 5 monoclonal antibodies (MAbs) showed a positive signal with GNNV-infected tissue or cells, but only the result of MAb 9D is presented here. Positive signals (arrows) appeared in the (a) bipolar and ganglion layers of the retina in GNNV-infected grouper eye and in the (c) cytoplasm of GNNV-infected GF-1 cells. No positive marking appeared in the GNNV-infected grouper eye staining with IPNV-specific rabbit antiserum (b) or non-infected GF-1 cells (d). Scale bar $=50 \mu \mathrm{m}$ in (a) and (b), and $100 \mu \mathrm{m}$ in (c) and (d) 
fied GNNV from GF-1 cells, were coated on the plate separately. All 5 MAbs reacted with purified GNNV from infected GF-1 cells. Only MAbs 9B, 2E and 12E were able to react with recombinant GNNV coat protein (Table 1).

\section{Immunohistochemistry of infected grouper tissues and cells}

When the 5 MAbs reacted with the experimentally GNNV-infected grouper tissues, specific immunostaining was observed mostly in cells of the bipolar and ganglionic layer of the retina (Fig. 1a). All 5 MAbs reacted with GNNV-infected GF-1 cells and positive signals were found only in the cytoplasm (Fig. 1c). No positive signal was found in the GNNV-infected retina using IPNV-specific rabbit antiserum (Fig. 1b) or in the non-infected GF-1 cells (Fig. 1d).

\section{Neutralization test}

The neutralizing effects of the 5 MAbs against 4 NNV strains representing 4 different genotypes, were expressed by the logarithm of the neutralization index (NI) in Table 2. In general, the neutralization indices of $<10\left(\log _{10} \mathrm{NI}<1\right)$ are considered not significant, indices between 10 and $50\left(\log _{10}\right.$ NI 1.0 to 1.6$)$ are questionable, and indices $>50\left(\log _{10} \mathrm{NI}>1.7\right)$ are significant. Therefore, all 5 MAbs neutralized GNNV, TPNNV and BFNNV. However, SJNNV was only neutralized by $\mathrm{MAb} 2 \mathrm{E}$ and 10G.

\section{Capture ELISA}

To construct a capture ELISA system, several combinations of capture antibody and detection antibody have been tested. When GNNV-specific RPAbs were used as the capture $\mathrm{Ab}$, and MAbs $2 \mathrm{E}$ or 9D were used as the detection antibody, the sensitivity of $\mathrm{RPAb} / \mathrm{MAb}$ 9D combination was about 4.5 times higher than that of RPAb/MAb 2E (data not shown). However, when the MAb was used as a capture antibody and GNNV-specific RPAbs were used as detection antibodies, the sensitivity of the MAb 9D/RPAb combination was similar to that of MAb 2E/RPAb. In addition, the background values of the MAb 2E/ $\mathrm{RPAb}$ and MAb 9D/RPAb combinations were much lower than those of the RPAb/2E and RPAb/9D combinations.

All immunoassays were carried out in duplicate and the results were very consistent, so only 1 of the duplicated results was demonstrated in Figs. $2 \& 3$.
The OD values of the negative control using PBS instead of virus for capture ELISA were 0.07 to 0.08 . All the OD values shown in Figs. 2 \& 3 have been subtracted from the OD value of the negative control. The $\mathrm{OD}_{405}$ values of the capture ELISA for different virus dilutions were much higher than those of the indirect ELISA (Fig. 2).

The OD values for the MAb 9D (IgM), with different virus dilutions, were very similar to those of MAb 2E (IgG) (Fig. 3). In Fig. 3a, the R-squared of the regression curve of MAb 9D between 10 and $50 \mathrm{ng} \mathrm{well}{ }^{-1}$ is 0.9909. In Fig. 3b, the

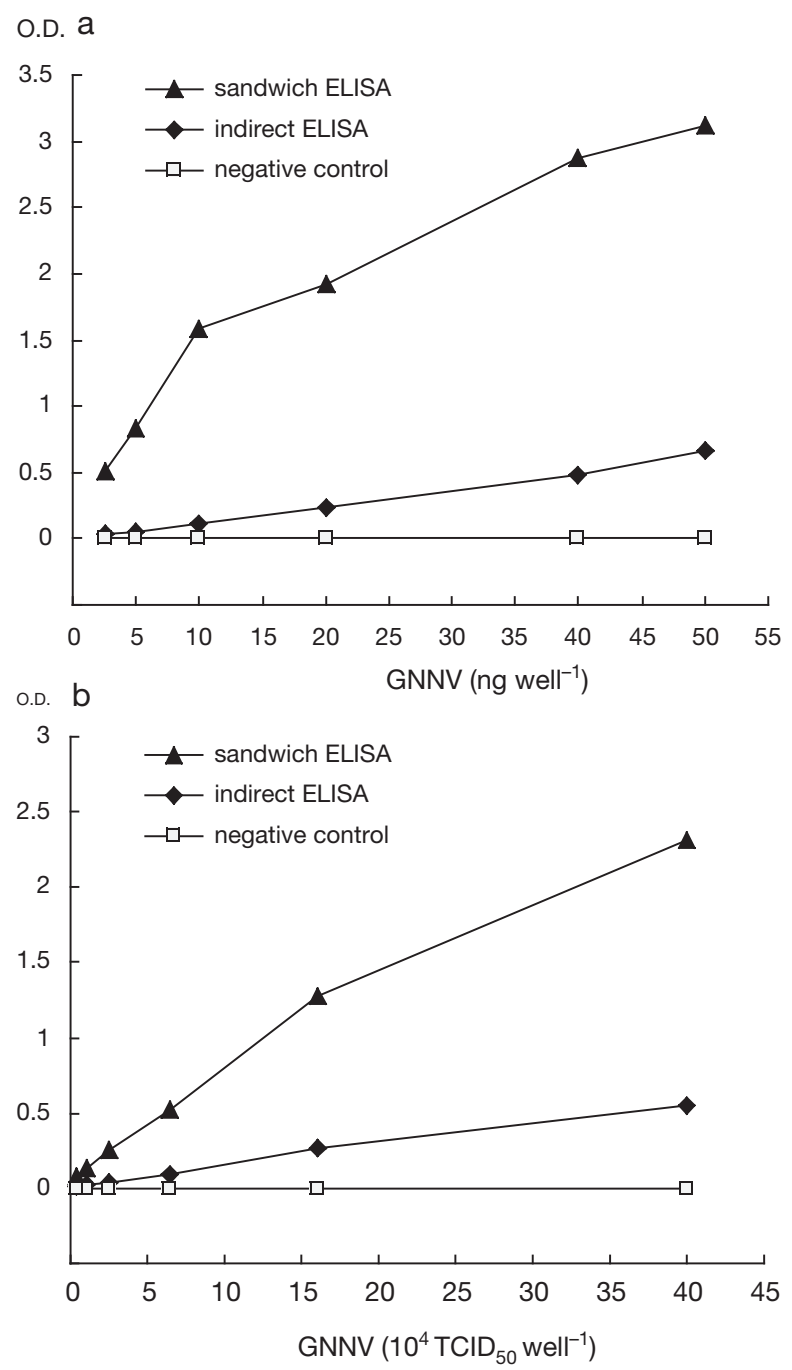

Fig. 2. Comparison of the sensitivity between indirect and capture ELISA. MAb 9D was used as the detection antibody for the indirect ELISA. For the capture ELISA, MAb 9D was used as the capture antibody and GNNV-specific rabbit polyclonal antibody was used as the detection antibody. The antigen used in (a) was purified GNNV and in (b) a supernatant culture of GNNV-infected GF-1 cells. All optical density (OD) values presented were substracted from the OD value of the negative control 

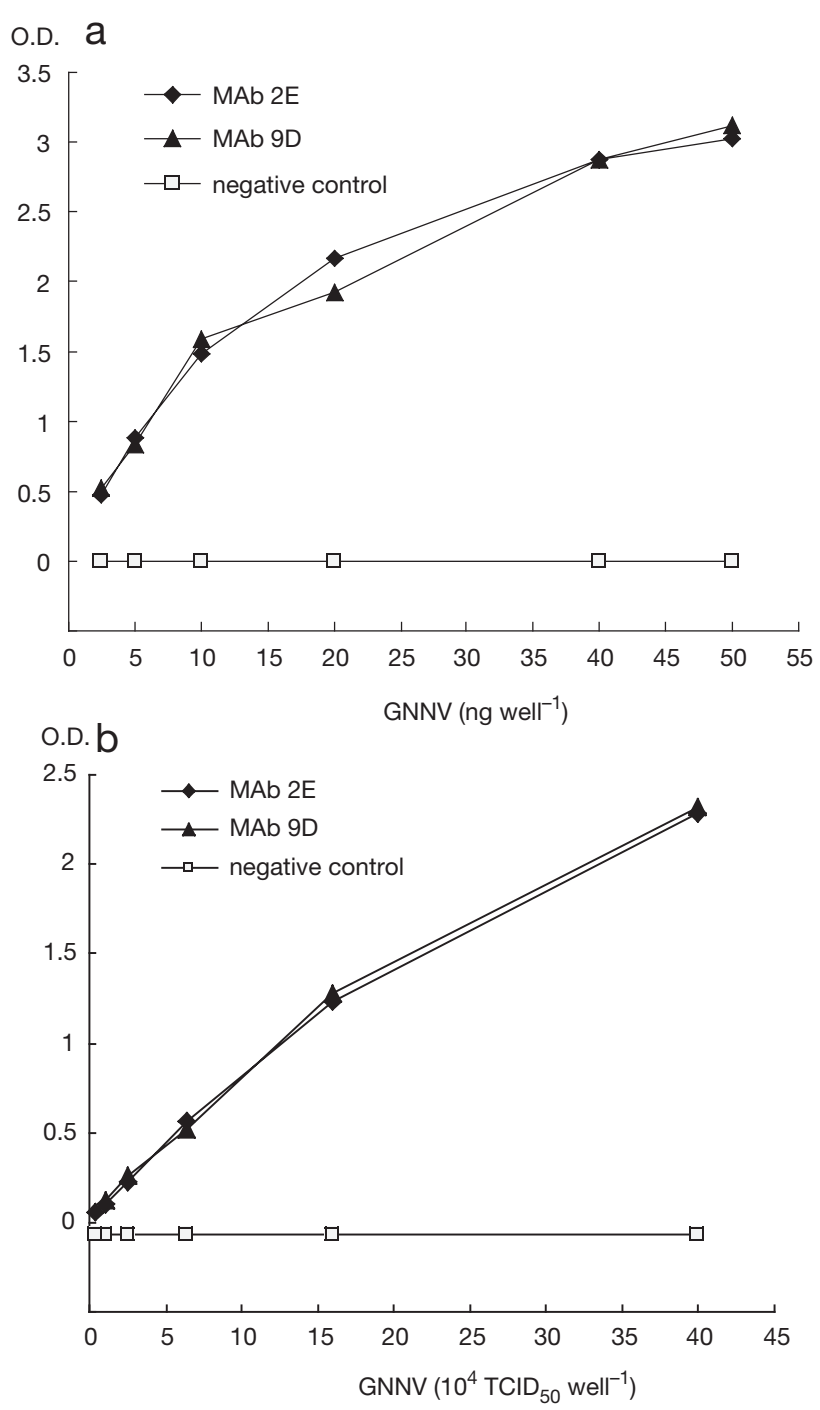

Fig. 3. Comparison of the sensitivity of capture ELISA between MAbs 2E (IgG) and 9D (IgM). The MAb was used as a capture antibody and rabbit polyclonal antibodies were used as the detection antibodies. The antigen used in (a) was purified GNNV and in (b) the culture supernatant of GNNVinfected GF-1 cells. OD: optical density

R-squared of the regression curve of MAb 9D between 0.4 and $40 \times 10^{4}$ TCID $_{50}$ well $^{-1}$ is 0.9813 . If we define $\mathrm{OD}_{405}$ values higher than 0.5 as positive results, the sensitivity of the capture ELISA developed in this study was $2.5 \mathrm{ng}$ well $^{-1}$ or $6.5 \times$ $10^{4}$ TCID $_{50}$ well $^{-1}$.

\section{DISCUSSION}

In the present study, 5 neutralizing MAbs for the nodavirus (G9508KS) from grouper Epinephelus coioides, Hamilton were established, characterized and applied in order to construct a capture ELISA system.

Both MAbs 9D and 10G showed a negative reaction to the indirect ELISA with recombinant capsid protein of GNNV expressed by Eschericha coli, a prokaryotic system without post-translational modification, including folding, phosphorylation and carboxylation. However, they showed a positive reaction to the NNV capsid protein, prepared from GNNV-infected GF-1 cells in a Western blot, indicating that the epitopes recognized by MAbs 9D and 10G were conformation-independent. The GNNV capsid protein was proved to be glycoprotein by periodic staining (Chi et al. 2001). Therefore, the neutralizing epitopes defined by MAbs 9D and 10G are suggested to be on the non-polypeptide part of the capsid protein, and it is highly likely that they are on the carboxyl group of the capsid protein.

Although MAbs 2E, 9B and 12E all showed negative results in a Western blot, they recognized different conformation-dependent epitopes. The epitope of $\mathrm{MAb} 2 \mathrm{E}$ is different from the epitopes of MAbs 9B and $12 \mathrm{E}$, because MAb 2E can neutralize SJNNV, while MAbs 9B and 12E are unable to. An antibody-blocking assay (an ELISA competition assay) between MAbs 9B and $12 \mathrm{E}$ was performed. The additivity indices (AI) for 2 MAbs that bind independently at different epitopes is 100, whereas, the AI for 2 MAbs that bind at the same epitope and/or completely block each other will be 0 (Friguet et al. 1983). The AI of the 9B/12E combination was slightly higher than 100, so they recognized different epitopes (data not shown).

The retina is one of the target organs for NNV amplification (Chi et al. 2001, Lai et al. 2001, Munday et al. 2002). Moreover, NNV is an RNA virus and its capsid protein assembles in the cytoplasm (Chi et al. 1997, 2001). The positive labeling of the 5 MAbs with NNV in the retina of infected grouper and in the cytoplasm of infected GF-1 cells confirmed that these 5 MAbs are useful for the localization of GNNV in the infected fish and in the cells used for immunohistochemistry.

Nishizawa et al. (1999) indicated that SJNNV could be serologically discriminated from the other $3 \mathrm{NNV}$ genotypes by 2 SJNNV-specific MAbs. Skliris et al. (2001) reported that European NNV isolates belonging to the RGNNV genotype were serologically different from the SJNNV genotype in cross neutralization tests by RGNNV-specific and SJNNV-specific polyclonal antibodies. Mori et al. (2003) classified 20 NNV isolates, including representatives of 4 genotypes, into 3 serological groups (A, B, C) by neutralization tests using rabbit antisera against strains of each genotype. The sero-groupings are in part consistent with their genotypes, i.e. serotype A for SJNNV, serotype B for TPNNV, and serotype C for RGNNV and BFNNV. In the present study, MAbs 9B, 9D and 12E were unable 
to effectively neutralize the SJNNV $\left(\log _{10} \mathrm{NI}<1.7\right)$, but could significantly neutralize the GNNV, TPNNV and BFNNV. This result reconfirms that the serological relationships among the RGNNV, BFNNV and TPNNV genotypes are closer than the relationships between the SJNNV and the other 3 genotypes. It is worth noting that MAbs 9B, 9D and 12E could be used to distinguish the SJNNV genotype from the RGNNV, BFNNV and TPNNV genotypes.

The major advantage of using a capture ELISA is that the antigen does not need to be purified prior to use, and the assays are very specific (Hyatt et al. 1991). Moreover, for the indirect ELISA test, sample viruses are coated directly on the EIA plate, whereas in the capture ELISA method, the antigens are placed between 2 layers of antibodies. The affinity and specificity of the capture ELISA are higher than that of the indirect ELISA. In addition, using capture ELISA to primarily sieve the sample through the capture antibody can prevent excessive protein in the sample, which can decrease the adsorptive rate of the antigen, or a cross reaction to other proteins that cause excessively high background values.

The affinity of IgG is usually considered to be higher than that of IgM. However, IgG is a monomer and IgM a pentamer. When RPAbs were used as capture antibodies, most of the viral epitopes were blocked by the polyclonal antibodies and fewer of them were left for the remaining MAbs, which were used as detection antibodies. MAb 2E is an IgG and Mab 9D is an IgM; therefore, the OD of the RPAb/MAb 2E was much lower than that of the RPAb/MAb 9D. On the contrary, when MAbs were used as capture antibodies, only MAb-specific epitopes were blocked. There were still many other epitopes on the viral particles recognizable by the remaining polyclonal antibodies, and therefore, the OD values of MAb/RPAb were higher than those of RPAb/MAb. This also explains why the OD value of the MAb 9D/RPAb combination was similar to that of the MAb 2E/RPAb combination.

An indirect ELISA using the anti-SJNNV serum was developed by Arimoto et al. (1992) and the sensitivity was $5 \mathrm{ng}$ well $^{-1}$ when an absorbance value higher than 0.1 was judged as positive. Unfortunately, this ELISA system is not applicable to other fish nodaviruses. However, the capture ELISA in the present study could be applied for the detection of NNV isolates representing the $4 \mathrm{NNV}$ genotypes. Mushiake et al. (1992) developed an indirect ELISA procedure for detecting antiserum against SJNNV in fish, but they found no correlation between the presence of viral Ag in the ovary and the presence of antibodies in the serum. Breuil et al. (2000) suggested that the detection of antisera against NNV could be a valuable method for detecting seronegative fish, but that it still should be used in conjunction with the antigen detection in biopsies.

The RT-PCR established by Nishizawa et al. (1994) has been the main tool for detecting NNV antigen. The minimal titer from which RT-PCR amplicons (T4) of the SGWak97 isolate were obtained was $10^{5} \mathrm{TCID}_{50}$ (Iwamoto et al. 2001), and the lowest viral titer from which RT-PCR amplicon (T2) of the G9508KS isolate was obtained in our lab was about $10^{4}$ to $10^{5} \mathrm{TCID}_{50}$ (data not shown). Hence, the sensitivity of the capture ELISA $\left(6.5 \times 10^{4} \mathrm{TCID}_{50}\right)$ was found to be similar to that of the RT-PCR mentioned.

In the present study, MAb/RPAb was found to be the best combination for the capture ELISA system, and the OD values of the capture ELISA system using MAb 9D or 2E as capture antibodies were higher than those of the indirect ELISA method. The capture ELISA system could also be useful to determine the absolute amounts of NNV protein antigen by comparing the readings with the standard cure obtained, using a known amount of pure antigen. It is hoped that the capture ELISA system can be applied to quantify NNV protein in tissue extracts of experimentally infected fish in future studies.

Acknowledgements. The authors would like to thank Dr. T. Nakai for supplying E-11 cells and 3 NNV strains (TPKag93, JFIwa98 and SJNag93), and Dr. H. L. Yang for providing the purified recombinant GNNV coat protein expressed in Escherichia coli. We also thank Y. L. Shieh for taking care of the hybridoma cells. This work was financially supported by the Fisheries Administration, Council of Agriculture of the Republic of China under contract No. 90AS-2.1.1-FA-F1(14).

\section{LITERATURE CITED}

Arimoto M, Mushiake K, Mizuta Y, Nakai T, Muroga K, Furusawa I (1992) Detection of striped jack nervous necrosis virus (SJNNV) by enzyme-linked immunosorbent assay (ELISA). Fish Pathol 27:191-195

Bouvet JP, Pires R (1991) One-step purification of murine monoclonal antibodies of the IgM class. J Immunol Methods 145:263-266

Breuil G, Pepin JF, Castric J, Fauvel C, Thiery R (2000) Detection of serum antibodies against nodavirus in wild and farmed adult sea bass: application to the screening of brood-stock in sea bass hatcheries. Bull Eur Assoc Fish Pathol 20:95-100

Chi SC, Lo CF, Kou GH, Chang PS, Peng SE, Chen SN (1997) Mass mortalities associated with viral nervous necrosis (VNN) disease in two species of hatchery-reared grouper, Epinephelus fuscogutatus and Epinephelus akaara (Temminck \& Schlegel). J Fish Dis 20:185-193

Chi SC, Hu WW, Lo BJ (1999a) Establishment and characterization of a continuous cell line (GF-1) derived from grouper, Epinephelus coioides (Hamilton): a cell line susceptible to grouper nervous necrosis virus (GNNV). J Fish Dis 22:173-182

Chi SC, Lin SC, Su HM, Hu WW (1999b) Temperature effect on nervous necrosis infection in grouper cell line and in grouper larvae. Virus Res 63:107-114 
Chi SC, Lo BJ, Lin SC (2001) Characterization of grouper nervous necrosis virus (GNNV). J Fish Dis 24:3-13

Chi SC, Shieh JR, Lin SJ (2003) Genetic and antigenic analysis of betanodaviruses isolated from aquatic organism in Taiwan. Dis Aquat Org 55:221-228

Comps M, Pepin JF, Bonami JR (1994) Purification and characterization of two fish encephalitis viruses (FEV) infecting Lates calcarifer and Dicentrarchus labrax. Aquaculture 123:1-10

Comps M, Trindade M, Delsert CL (1996) Investigation of fish encephalitis viruses (FEV) expression in marine fishes using DIG-labelled probes. Aquaculture 143:113-121

Ey PL, Prowse SJ, Jenkin CR (1978) Isolation of pure IgG1, IgG2A, IgG2B immunoglobulins from mouse serum using protein A-Sepharose. Immunochemistry 15: 429-436

Frerichs GN, Rodger HD, Peric Z (1996) Cell culture isolation of piscine neuropathy nodavirus from juvenile sea bass, Dicentrarchus labrax. J Gen Virol 77:2067-2071

Friguet B, Djavadi-Ohaniance L, Pages J, Bussard A, Golderg M (1983) A convenient enzyme-linked immunosorbent assay for testing whether monoclonal antibodies recognize the same antigenic site. Application to hybridomas specific for the b2-subunit of Esherichia coli tryptophan synthase. J Immunol Methods 60:351-358

Hedge A, The HC, Lam TJ, Sin YM (2003) Nodavirus infection in freshwater ornamental fish, guppy, Poicelia reticulate - comparative characterization and pathogenicity studies. Arch Virol 148:575-586

Hyatt AD, Eaton BT, Hengstberger S, Russel G (1991) Epizootic haematopoitic necrosis virus: detection by ELISA, immunohistochemistry and immunoelectron-microscopy. J Fish Dis 14:605-617

Iwamoto T, Mori K, Arimoto M, Nakai T (1999) High permissivity of the fish cell line $\mathrm{SSN}-1$ for piscine nodaviruses. Dis Aquat Org 39:37-47

Iwamoto T, Nakai T, Mori K, Arimoto M, Furusawa I (2000) Cloning of the fish cell line SSN-1 for piscine nodaviruses. Dis Aquat Org 43:81-89

Iwamoto T, Mori K, Arimoto M, Nakai T (2001) A combined cell-culture and RT-PCR method for rapid detection of piscine nodavirus. J Fish Dis 24:231-236

Lai YS, Chiu HC, Murali S, Guo IC, Chen SC, Fang K, Chang

Editorial responsibility: Jo-Ann Leong,

Kaneohe, Hawaii, USA
CY (2001) In vitro neutralization by monoclonal antibodies against yellow grouper nervous necrosis virus (YGNNV) and immunolocalization of virus infection in yellow grouper, Epinephelus awoara (Temminck \& Schlegel). J Fish Dis 24:237-244

Le Breton A, Grisez L, Sweetman J, Ollevier F (1997) Viral nervous necrosis (VNN) associated with mass mortalities in cage-reared sea bass, Dicentrarchus labrax L. J Fish Dis 20:145-151

Mahy BWJ, Kangro HO (1996) Neutralization. In: Mahy BWJ, Kangro HO (eds) Virology method manual. Academic Press, London, p 108-109

Mori K, Nakai T, Muroga K, Arimoto M, Mushiakc K, Furuswa I (1992) Properties of a new virus belong to Nodaviridae found in larval stripped jack (Pseudocaranx dentex) with nervous necrosis. Virology 187:378-371

Mori K, Mangyoku T, Iwamoto T, Arimoto M, Tanaka S, Nakai $T$ (2003) Serological relationships among genotypic variants of betanodavirus. Dis Aquat Org 57:19-26

Munday BL, Kwang J, Moody N (2002) Betanodavirus infections of teleost fish: a review. J Fish Dis 25:127-142

Mushiake K, Arimoto M, Furuwawa T, Furusawa I, Nakai T, Muroga K (1992) Detection of antibodies against striped jack nervous necrosis virus (SJNNV) from brood stocks of striped jack. Nippon Suisan Gakkaishi 58:2351-2356

Nishizawa T, Mori K, Nakai T, Furusawa I, Muroga K (1994) Polymerase chain reaction amplification of RNA of striped jack nervous necrosis virus (SJNNV). Dis Aquat Org 18: 103-107

Nishizawa T, Kise M, Nakai T, Muroga K (1995) Neutralizing monoclonal antibodies to striped jack nervous necrosis virus (SJNNV). Fish Pathol 130:111-114

Nishizawa T, Furuhashi M, Nagal T, Nakai T, Muroga K (1997) Genomic classification of fish nodaviruses by molecular phylogenetic analysis of the coat protein gene. Appl Environ Microbiol 63:1633-1636

Nishizawa T, Tankano R, Muroga K (1999) Mapping a neutralizing epitope on the coat protein of striped jack nervous necrosis virus. J Gen Virol 80:3032-3027

Skliris GP, Krondiris JV, Sideris DC, Shinn AP, Starkey WG, Richard RH (2001) Phylogenetic and antigenic characterization of new fish nodaviruses from Europe and Asia. Virus Res 75:59-67

Submitted: January 2, 2004; Accepted: July 7, 2004 Proofs received from author(s): December 10, 2004 